\title{
Efficient Production of Porcine Circovirus Type 2 Capsid Protein using Baculovirus
}

\author{
Jun Beom Lee, Sung Min Bae, Hee Jung Kim, Won Woo Lee, Won Il Heo, Tae Young Shin, Jae Bang Choi, \\ and Soo Dong Woo* \\ Department of Agricultural Biology, College of Agriculture, Life \& Environment Science, Chungbuk National University, \\ Cheongju 361-763, Korea
}

(Received 28 January 2012; Accepted 08 March 2012)

Porcine circovirus type 2 (PCV2) is a single-stranded circular DNA virus associated with Postweaning multisystemic wasting syndrome (PMWS), which is considered to be an important infectious swine viral disease. PCV2 capsid protein encoded by ORF2 is a structural protein and expected as the high immunogenicity protein. In this study, we generated recombinant baculovirus containing ORF2 of PCV2 and analyzed the optimal conditions for the production of capsid protein in insect cell. Production and status of recombinant capsid protein in insect cell were confirmed by SDSPAGE and Western blot analysis using His tag antibody and anti-PCV2 serum. The yield of recombinant capsid protein was high like as shown visible on SDS-PAGE. Optimal multiplicity of infection (MOI) and infection time of recombinant virus were determined as 5 MOI and 4 days, respectively. ORF2 is known to have $N$ linked glycosylation site, but we couldn't detect the glycosylation of recombinant protein in insect cells.

Key words: Baculovirus, Capsid protein, Glycosylation, Porcine circovirus type 2, ORF2

\section{Introduction}

Postweaning multisystemic wasting syndrome (PMWS) is a viral disease which is characterized by progressive weight loss, respiratory and digestive disorders in

\footnotetext{
*To whom the correspondence addressed

Department of Agricultural Biology, College of Agriculture, Life \& Environment Science, Chungbuk National University, Cheongju 361-763, Korea.

Tel: +82-043-261-2553; Fax: +82-043-271-4414;

E-mail: sdwoo@cbnu.ac.kr
}

postweaned pigs. Since PMWS was first identified in western Canada in 1991 (Allan et al., 1998; Clark, 1997; Meehan et al., 1998), PMWS has become an economically important and serious disease in the world (Allan and Ellis, 2000; Trundova and Celer, 2007). Porcine circovirus type 2 (PCV2), a single-stranded circular DNA virus associated with PMWS of swine, has two major open reading frames, ORF1 and ORF2 (Nawagitgul et al., 2000). ORF1 encodes a replicase protein essential for viral DNA replication. ORF2 encodes the $28 \mathrm{kDa}$ capsid protein, which is a unique structural protein of the virus. The capsid protein encoded by ORF2 has type-specific epitopes (Liu et al., 2001; Mahe et al., 2000) and is very immunogenic and associated with the induction of neutralizing antibodies (Pogranichnyy et al., 2000). This strongly reacts with serum from PCV2-infected swine, and acts as major targets for the immune responses of the infected animals (Liu et al., 2004). Thus, one approach to control PCV2 widespread was the use of the capsid protein of PCV2 as subunit vaccine (Fan et al., 2007), and its potential capability is worth in diagnostic assays as well as vaccine development (Liu et al., 2008; Nawagitgul et al., 2002).

The baculovirus expression vector system (BEVS) has long been used to produce and to confirm molecular characteristic of various heterologous genes for the various research and industrial purposes including development of vaccine (Choi et al., 1999; Maeda, 1994; Matsuo et al., 2006, O'Reilly et al., 1992). This system has unique features and many advantages that are cost reducible production, harmless to humans, efficient expression, proper post-translational modification, and correct conformation (Liu et al., 2008).

In this study, we generated recombinant baculovirus to express PCV2 capsid protein and investigated optimal conditions for the efficient production of recombinant protein in insect cells. 


\section{Materials and Methods}

Cloning and generation of recombinant baculovirus Viral DNA was extracted from the PCV2 KSY-1 strain (GenBank: AF454546), and the full-length ORF2 of PCV2 was amplified by PCR using primer. Primer sequences were 5, AGATCTATGACGTATCCAAGGAGG 3' and 5' CTCGAGTTAGTGGTGGTGGTGGTGGTGGGGGTTAAGTGGG 3'. The forward primer contained the BglII site (under lined) before the start codon, and the reverse primer contained the 6x His and XhoI site (under lined) before and after the stop codon, respectively. The amplified ORF2 fragment was purified by using a gel extraction kit and was cloned into the T\&A cloning vector (RBC bioscience). After obtaining a sufficient plasmid DNA, it was digested with $B g l \mathrm{II}$ and $X h o$ I. The purified $730 \mathrm{bp}$ fragment was appropriately ligated into the baculovirus transfer vector pBacPAK9 (Clontech, CA) using ligation kit (TaKaRa, Japan).

The Spodoptera frugiferda cell line (Sf21) was maintained with SFM (Gibco BRL, USA) and seeded into T-25 flask (SPL Co. Ltd., Korea). Transfection mixture containing bAcGOZA (Je et al., 2001) and recombinant transfer vector was mixed with Lipofectin (Invitrogen, USA) and placed in $27^{\circ} \mathrm{C}$ for $30 \mathrm{~min}$. Cells were transfected with transfection mixture drop by drop and placed at room temperature. After $4 \mathrm{hrs}$ of incubation, the medium was removed and replaced with $5 \mathrm{ml}$ fresh insect cell culture medium SFM. After 5 days, the supernatant was harvested. A standard plaque assay procedure was used to obtain viral plaques from dilutions of the media harvested from the co-transfections (O'Reilly et al., 1992). The purified recombinant virus was propagated in Sf21 cells. The titer was expressed as plaque forming units (pfu) per milliliter according to standard method.

\section{Protein expression}

For the protein expression, Sf21 cells were seed at a concentration of $1.0 \times 10^{6}$ cells/well into 6 well tissue culture plate and infected with recombinant virus. After infection, the culture supernatant was harvested by centrifugation at $1,000 \mathrm{~g}$ for $5 \mathrm{~min}$, washed with PBS and resuspended in lysis buffer (iNtRON, Korea). The resuspended cells were lysed by sonication and then mixed with protein sample buffer and boiled at $100^{\circ} \mathrm{C}$ for $10 \mathrm{~min}$.

Prepared protein samples were electrophoresed on $12 \%$ SDS-PAGE gel, and separated proteins were stained with Coomassie brilliant blue and transferred onto a nitrocellulose membrane, respectively. Western blot hybridization was carried out as follows. Membrane was blocked with $5 \%$ skim milk, and reacted with anti-His mouse monoclonal antibody (abm Inc., CA) or anti-PCV2 serum, and

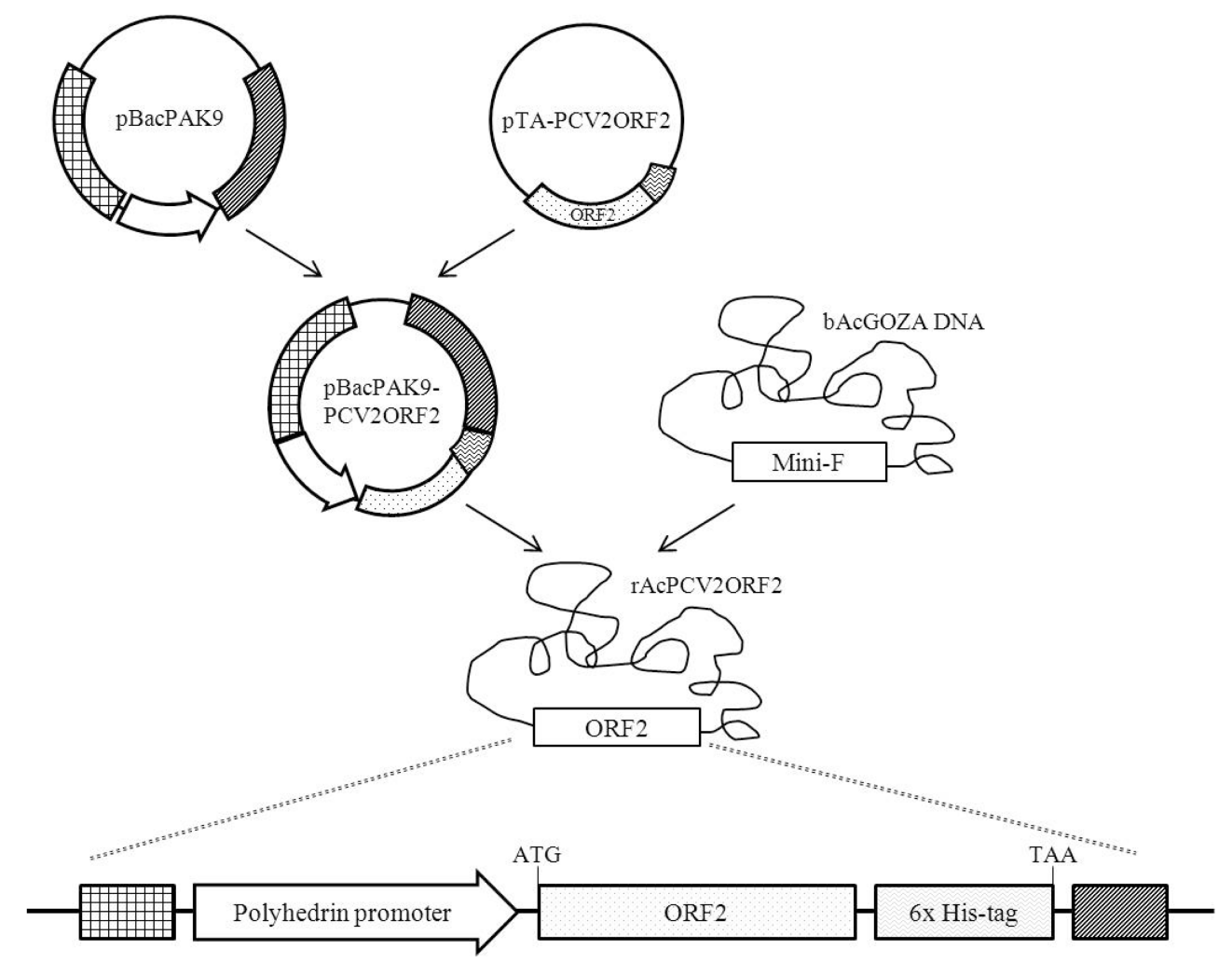

Fig. 1. Schematic representation for the generation of recombinant virus. 
HRP-linked anti mouse IgG (Cell signaling, USA) or antispecies antibody for secondary antibody. The blots were washed with $0.1 \%$ TBS-Tween buffer, and visualized using the ECL Western Blotting Detection System (Elpis Biotech, Daejeon, Korea).

\section{Glycosylation analysis}

Glycosylation of recombinant protein was determined whether it is glycoprotein or not using Gelcode Glycoprotein Staining Kit (Pierce biotechnology, USA). For linked site confirmation, the infected medium was replaced with fresh serum-free insect cell culture medium including $5 \mathrm{ug} / \mathrm{ml}$ tunicamycin or final concentration of 3 mM Benzyl-N-acetyl- $\alpha$-D-galactosaminide (BAG). The harvested cells were immunoblotted by the methods previously described for protein analysis using SDS-PAGE and Western blot hybridization.

\section{Results and Discussion}

\section{Generation of recombinant baculovirus}

ORF2 of PCV2 was successfully amplified from PCV2 KSY-1 strain and its sequence was confirmed. To generate the recombinant baculovirus, Sf21 cells were co-transfected with a mixture of bAcGOZA and pBacPAK9PCV2ORF2 (Fig. 1). Purified recombinant baculovirus was achieved by plaque assay method and its purity was confirmed by PCR and restriction enzyme analysis (data not shown). The recombinant virus was named as rAcPCV2ORF2 (Fig. 1).

\section{Expression of PCV2 capsid protein}

To analyze the expression of the recombinant capsid protein, Sf21 cells were infected with rAcPCV2ORF2 at 1 MOI and harvested at 3 days post infection (p.i.). Expression of the recombinant protein was analyzed by SDSPAGE and Western blot hybridization. The recombinant capsid protein at about $28 \mathrm{kDa}$ corresponding to the expected molecular size of capsid protein with $6 \mathrm{x}$ His-tag was observed clearly on SDS-PAGE and detected by Western blot hybridization analysis using $6 x$ His-tag antibody (Fig. 2). The recombinant protein expressed in the infected Sf 21 cells was only observed in cell lysate supernatant (Fig. 2). Although there is previous report about the formation of capsid particle when ORF2 is expressed in insect cells (Fan et al., 2007), we could not detect recombinant protein in cell lysate pellet because of insufficient centrifugation speed. The recombinant capsid protein was also detected with anti-PCV2 serum (Fig. 2C). This result indicates that recombinant capsid protein produced in insect cells has immunogenicity against PCV2. Above
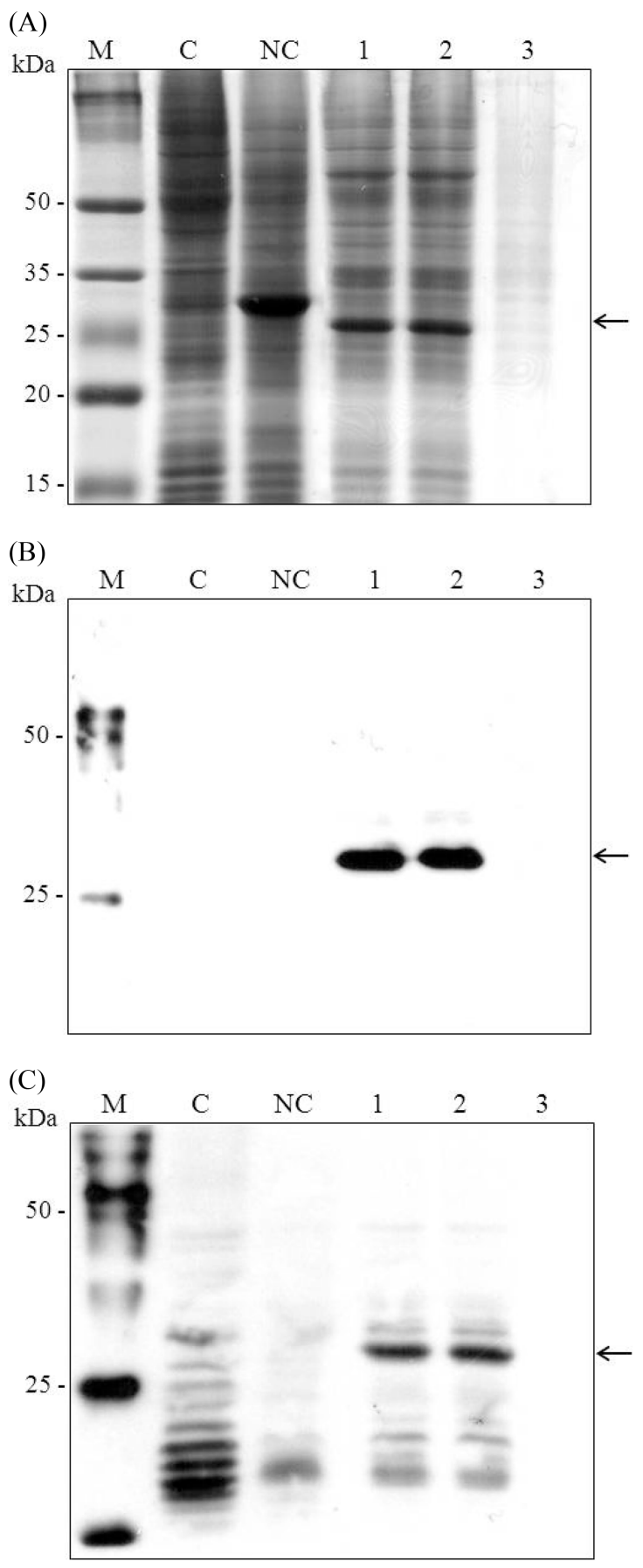

Fig. 2. Analysis of expression state of PCV2 capsid protein in Sf21 cells. After collection of virus infected cells, protein samples were prepared from total cell lysate, supernatant of cell lysate and pellet of cell lysate, respectively. Protein sample was separated on a $12 \%$ SDS-PAGE gel (A), and transferred to a nitrocellulose membrane for Western blot analysis using $6 \mathrm{x}$ His-tag antibodies (1:7500) (B) and anti-PCV2 serum (C). Lane $M$, protein marker; lane $C$, mock-infected Sf21 cells; lane NC, AcNPV (wild type); lane 1, total cell lysate; lane 2, supernatant; lane 3, pellet. Recombinant proteins are indicated with arrows. 
(A)

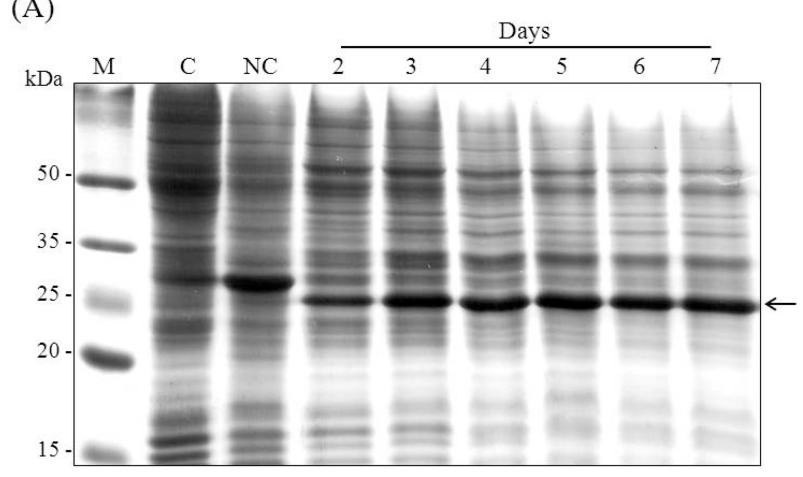

(B)

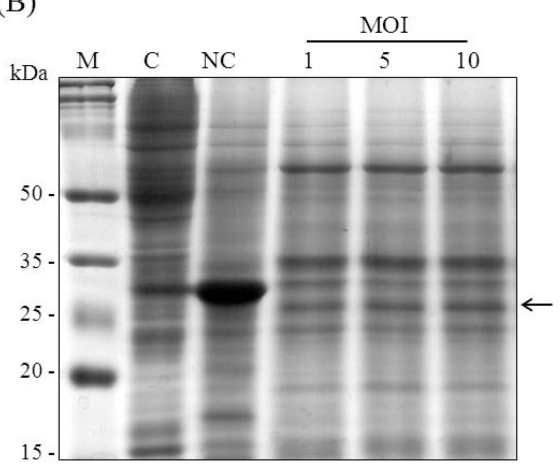

Fig. 3. Time course and optimal titer analysis for the production of PCV2 capsid protein in Sf21 cells. The cells were infected with recombinant virus on various times (A) and for various titers (B). Each protein sample was separated on a $12 \%$ SDS-PAGE. Lane M, protein marker; lane C, mockinfected Sf21 cells; lane NC, AcNPV (wild type). Recombinant proteins are indicated with arrows.

results showed that ORF2 could be expressed efficiently in insect cells and this may be used directly as the antigen for the vaccine.

\section{Optimization of recombinant protein expression in Sf21 cells}

To determine optimal titer and infection time for the production of recombinant protein the cells infected with rAcPCV2ORF2 were harvested daily until 7 days p.i. Expression of recombinant protein was first detected on day 2 and peaked on day 4 p.i. (Fig. 3A). The longer infection time did not influence the process of recombinant protein production. After infection with frequently used MOI 1, 5 and 10 the recombinant protein yield was compared. As the result we determined $5 \mathrm{MOI}$ as the optimal titer to infect cells because 5 and 10 MOI showed similar production of recombinant protein (Fig. 3B).

\section{Glycosylation analysis of recombinant protein}

The glycosylation of recombinant protein was analyzed
(A)

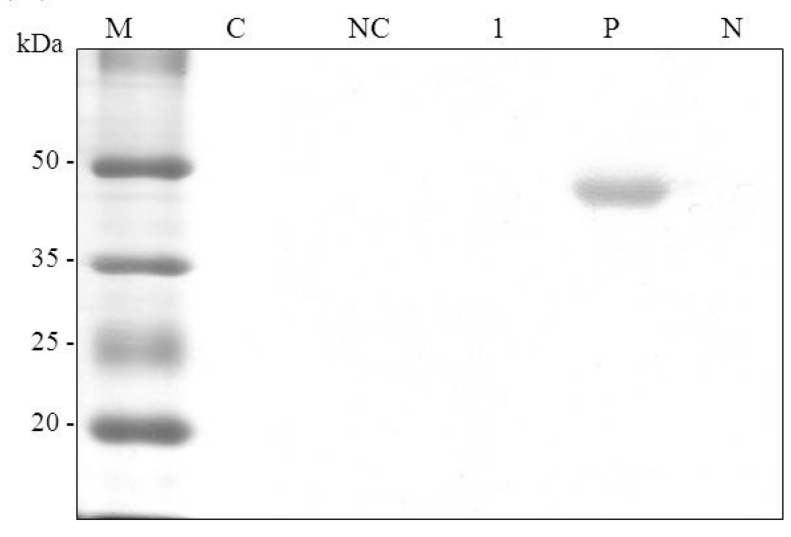

(B)

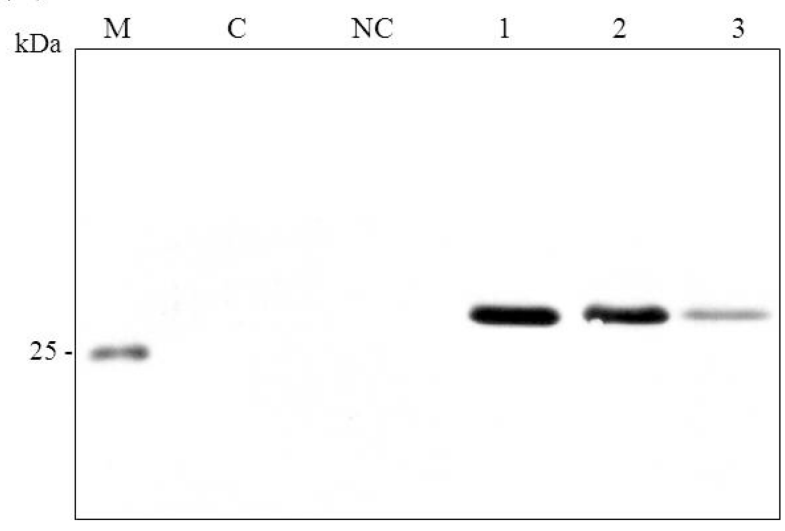

Fig. 4. Glycosylation confirmation of PCV2 capsid protein in Sf21 cells. Glycosylation was determined by staining method using Glycoprotein Staining Kit (A) and glycosylation inhibitor method using tunicamycin and Benzyl-N-acetyl- $\alpha-D-$ galactosaminide (BAG) (B). Lane $\mathrm{M}$, protein marker; lane $\mathrm{C}$, mock-infected Sf21 cells; lane NC, AcNPV (wild type); lane P, positive control; lane $\mathrm{N}$, negative control; lane 1, recombinant protein; lane 2, tunicamycin; lane $3, \mathrm{BAG}$ treatment.

by glycoprotein staining method (Fig. 4A) and treatment of glycosylation inhibitors (Fig. 4B) because ORF2 is known to have $N$-linked glycosylation site (Hamel et al., 1998). However, we could not identify glycosylation of recombinant capsid protein with these methods. Although putative amino acid sequence of the ORF2 possessed at least one glycosylation site (Hamel et al., 1998), there is no experimental report prove it until now. The glycosylation of recombinant glycoprotein in insect cells is not perfect compared to other vertebrate system but superior than other prokaryote system. Thus, the glycosylation of recombinant PCV2 capsid protein should be further analyzed.

We are currently investigating the enhanced production of recombinant PCV2 capsid protein which may be useful 
for the development of new, safe, effective and economical vaccines against PCV2.

\section{References}

Allan GM, Ellis JA (2000) Porcine circoviruses: a review. J Vet Diagn Invest 12, 3-14.

Allan GM, McNeilly F, Kennedy S, Daft B, Clarke EG, Ellis JA, Haines DM, Meehan BM, Adair BM (1998) Isolation of porcine circovirus-like viruses from pigs with a wasting disease in the USA and Europe. J Vet Diagn Invest 10, 3-10.

Choi JY, Woo SD, Je YH, Kang SK (1999) Development of a novel expression vector system using Spodoptera exigua nucleopolyhedrovirus. Mol Cells 9, 504-509.

Clark EG (1997) Post-weaning multisystemic wasting syndrome. pp. 499-501, Proceedings of the American Association of Swine Practitioners.

Fan H, Ju C, Tong T, Huang H, Lv J, Chen H (2007) Immunogenicity of empty capsids of porcine circovirus type 2 produced in insect cells. Vet Res Commun 31, 487-496.

Hamel AL, Lin LL, Nayar GPS (1998) Nucleotide sequence of porcine circovirus associated with postweaning multisystemic wasting syndrome in pigs. J of Virol 72, 5262-5267.

Je YH, Chang JH, Choi JY, Roh JY, Jin BR, O'Reilly DR, Kang SK (2001) A defective viral genome maintained in Escherichia coli for the generation of baculovirus expression vectors. Biotechnology Letters 23, 575-582.

Liu C, Ihara T, Nunoya T, Ueda S (2004) Development of an ELISA based on the baculovirus-expressed capsid protein of porcine circovirus type 2 as antigen. J Vet Med Sci 66(3), 237-242.

Liu LJ, Suzuki T, Tsunemitsu H, Kataoka M, Ngata N, Takeda N, Wakita T, Miyamura T, Li TC (2008) Efficient production of type 2 porcine circovirus-like particles by a recombinant baculovirus. Arch Virol 153, 2291-2295.

Liu Q, Tikoo SK, Babiuk LA (2001) Nuclear localization of the ORF2 protein encoded by porcine circovirus type 2 . Virology 285, 91-99.
Maeda S (1994) Expression of foreign gene in insect cells using baculovirus vectors. In Insect cell biotechnology. Edited by Maramorosch, K \& Mclntosh A. Boca Raton: CRC Press; 1-31.

Mahe D, Blanchard P, Truong C, Arnauld C, Le Cann P, Cariolet R, Madec F, Albina E, Jestin A (2000) Differential recognition of ORF2 protein from type 1 and type 2 porcine circoviruses and identification of immunorelevant epitopes. J Gen Virol 81, 1815-1824

Matsuo E, Tani H, Lim C, Komoda Y, Okamoto T, Miyamoto H, Moriishi K, Yagi S, Patel AH, Miyamura T, Matsuura Y (2006) Characterization of HCV-like particles produced in a human hepatoma cell line by a recombinant baculovirus. Biochem Biophys Res Commun 340, 200-208.

Meehan BM, McNeilly F, Todd D, Kennedy S, Jewhurst VA, Ellis JA, Hassard LE, Clark EG, Haines DM, Allan GM (1998) Characterization of novel circovirus DNAs associated with wasting syndromes in pigs. J Gen Virol 79, 21712179.

Nawagitgul P, Morozov I, Bolin SR, Harms PA, Sorden SD, Paul PS (2000) Open reading frame 2 of porcine circovirus type 2 encodes a major capsid protein. J Gen Virol 81, 22812287.

Nawagitgul P, Harms PA, Morozov I, Thacker BJ, Sorden SD, Lekcharoensuk C, Paul PS (2002) Modified indirect porcine circovirus (PCV) type 2-based and recombinant capsid protein (ORF2)-based enzyme-linked immunosorbent assays for detection of antibodies to PCV. Clin Diagn Lab Immunol 9, 33-40.

O'Reilly DR, Miller LK, Luckow VA (1992) Baculovirus expression vectors: a laboratory manual. WH Freeman \& Co, New York.

Pogranichnyy RM, Yoon KJ, Harms PA, Swenson SL, Zimmerman JJ, Sorden SD (2000) Characterization of immune response of young pigs to porcine circovirus type 2 infection. Viral Immunol 13(2), 143-153

Trundova M, Celer V (2007) Expression of porcine circovirus 2 ORF2 gene requires codon optimized $E$. coli cells. Virus Genes 34, 199-204. 